\title{
World Confederation for Physical Therapy
}

\section{Africa Region-Second Regional Congress, Harare}

\section{- Jo Beenhakker}

The second regional congress was hosted by the Zimbabwe Physiotherapy Association during September 18-28 1996. With only 139 members belonging to the association, all physiotherapists were involved from the beginning and showed great commitment to assist in all stages of the organisation of the congress.

Prior to congress several courses were held which provided a variety of subjects. These included an update on cardio-respiratory management and an update on the management of patients with stroke by Johannesburg physiotherapists. Graham Smith ran successful pre and post congress courses on the management of sports injuries with emphasis on hip and groin injuries and the problem knee. Jostein Ellingsen, a teacher on the two year diploma course in manual therapy, was responsible for an introductory and advanced course on the Nordic approach to manual therapy in the management of the lumbar spine.

Other post congress courses offered by South Africans were a fresh approach to the management of child ren with brain damage by Pam Hansford and myofascial release by Marge Steffen. It was a pity that the course to be run by Stephanie Kemp on community-based rehabilitation in paediatrics was undersubscribed as this is surely a most worthwhile and essential area of physiotherapy in Africa.

In the mornings key note lectures by physiotherapists were given by Graham Smith, Mary Riley, Helen Myezwa and Marge Steffen, all of which were well received. Topics covered were tissue repair, motor learning, communitybased rehabilitation and healing of connective tissue. Further scientific presentations covered many areas of concern to the physiotherapists in Africa such as HIV and AIDS, cerebral palsy, referral patterns from medical practitioners and obligations to torture victims. Informed consent was discussed and it was stressed that in the physiotherapy / patient relationship mutual trust, respect and confidentiality were essential. The physiotherapist needs to ensure that there is effective communication in order to provide information on the benefits and risks that may be involved and to realise that the patient has the right to refuse treatment at any stage. The respect of the autonomy of the patient must be maintained throughout.

In the afternoons, workshops were given which unfortunately were too short for reasonable exchange of ideas. An interesting array of topics were offered however, such as research, acupuncture, management of survivors of torture, burns stroke, fitness training and pain control.

On the whole this congress was great success and achieved many of the goals set. There was good regional representation on the stage as well as in the audience, useful update of research and clinical expertise and fostering of regional identity. Congratulations to Passion Musa, the congress Chair, the scientific committee of Marlene Brand, Jenny Jelsma and Heather Dawson, to Carrie Lapham who organised the social programme and Stella Sigogo who coordinated the transport and buddy system. Participants were fetched from the airport and collected from and returned to their hotels each day by a small band of volunteers.

It will be South Africa's turn to host the next congress in 1998. It is hoped that the congress committee will soon be sending out notices of the date and venue of the third WCPT-Africa regional congress and will be inviting participants from Africa and further abroad. This is the only way that we will be able to match the entertaining social events and the well run and informative scientific programme that was offered at the second regional congress.

\section{The Smith and Nephew Educational Trust}

Smith and Nephew annually donate a Travel Bursary to members of the SASP in recognition of the long association of the Company with the physiotherapy profession.

\section{Criteria for the award of this annual bursary}

- The National Assembly selects the suitable candidate or candidates.

- The bursary is awarded to a physiotherapist who is presenting a paper at a local or overseas congress.

- The successful candidate will undertake to write an article relating to the paper presented, and to subinit this article to the Editor of the SA Journal Physiotherapy within six months of presenting the paper.
- If the paper has been published in the Proceedings of the Congress attended, prior permission for its publication in the SA Journal of Physiotherapy must be obtained from the Congress Secretariat).

- Applications from any physiotherapist who will be presenting a paper at a congress, must be submitted to the Head Office of the SASP, together with a short CV and motivation.

- The closing date for the 1997 Travel Bursary is 30 April 1997.

The South African Society of Physiotherapy is very grateful for this generous gesture by Smith and Nephew, which will be of particular value in these difficult economic times. 